\title{
Greenhouse gases emissions from waste management practices using Life Cycle Inventory model
}

\author{
Tsao-Chou Chen*, Cheng-Fang Lin \\ Graduate Institute of Environmental Engineering, National Taiwan University, 71, Chou-Shan Road, Taipei 10660, Taiwan
}

Received 31 May 2007; received in revised form 12 November 2007; accepted 12 November 2007

Available online 22 November 2007

\begin{abstract}
When exploring the correlation between municipal solid waste management and green house gas emission, the volume and physical composition of the waste matter must be taken into account. Due to differences in local environments and lifestyles the quantity and composition of waste often vary. This leads to differences in waste treatment methods and causes different volumes of greenhouse gases (GHGs), highlighting the need for local research. In this study the Life Cycle Inventory method was used with global warming indicator GHGs as the variables. By quantifying the data and adopting a region-based approach, this created a model of household MSWM in Taipei City, a metropolitan region in Taiwan. To allow analysis and comparison a compensatory system was then added to expand the system boundary. The results of the analysis indicated that out of all the solid waste management sub-models for a function unit, recycling was the most effective method for reducing GHG emissions while using kitchen food waste as swine feeding resulted in the most GHG emissions. As for the impact of waste collection vehicles on emissions, if the efficiency of transportation could be improved and energy consumption reduced, this will help solid waste management to achieve its goal of reducing GHG emissions.
\end{abstract}

(C) 2007 Elsevier B.V. All rights reserved.

Keywords: Solid waste management; Greenhouse gases; Life Cycle Inventory; Waste treatment

\section{Introduction}

In waste management, the critical environmental impact issues to consider include not only safe treatment and disposal of wastes but also system management of greenhouse gas generation. Solid waste treatment methods play some degree of impact on global warming [1]. Traditional sanitary landfill of organic wastes produces methane gas and the organic waste research (ORWARE) model used the life-cycle assessment (LCA) methodology to assess its impact from the aspect of GHG contribution [2]. To reduce GHG emissions, the U.S. EPA and International Council for Local Environmental Initiatives (ICLEI) collaborated together to launch the "Cities for Climate Protection Campaign". The purpose of this joint regional action plan was to achieve regional reductions in GHG emissions [3]. To understand and examine the correlation between municipal solid waste management (MSWM) and GHG discharge, this

\footnotetext{
* Corresponding author. Tel.: +886 2 27287268; fax: +886229685689. E-mail address: d91541013@ntu.edu.tw (T.-C. Chen).
}

study proposes to use the Life Cycle Inventory method with waste material flow on a regional municipal city level. This work will provide a data base of GHG emission figures for different regional household waste management schemes. The results can then be used to support the decision making process by waste management agencies or decision makers when choosing between solid waste management proposals in their GHG reduction action plan.

\section{Background and objectives}

Taipei City was selected as the case study in this study. Taipei City is located in the Taipei Basin in northern Taiwan, an island off the southeast coast of Asia. It has a total area of $271.7997 \mathrm{~km}^{2}$ with a population of approximately 2.63 million (12\% of Taiwan's total population) and population density of 9700 people per square kilometer. Since December 1985 all garbage from the city has been disposed of using the sanitary landfill method. Three incinerator plants were then completed in 1999 providing a total waste processing capacity of 3900 tonnes a day. Apart from incombustible waste, all Taipei City garbage is now 
sent to the incinerators. To reduce waste, increase recycling and overcome a shortage of landfill sites, a municipal waste volumebased collection fee policy was imposed in July 2000. This measurement reduced the quantity of total waste from an average of 2970 tonnes per day in 1999 to an average of 1291 tonnes per day by 2005 . To deal with the problem of organic kitchen waste that made up one-third of the household waste by volume as well as to achieve the objectives of "Zero Landfill" and "Total Recycling" by 2010 in its solid waste management strategy, the Taipei City Government made changes to its garbage collection service in 2003. In December 2003 all 198 garbage collection routes switched to a new format where kitchen waste and recyclable materials were collected at the same time as garbage but kept separate [4].

The "Kyoto Protocol" was devised to impose restrictions on the emission of GHGs in response to concerns over waste management's environmental impact and to slow down global warming. To implement the Kyoto Protocol, a better understanding must be achieved of GHG emission volumes throughout the waste management life cycle. The purpose of this study was therefore to quantify and assess the level of GHG contribution by each type of treatment method being practiced in Taipei City's regional household waste management process. To achieve this, a localized inventory model must be established that conforms to internationally accepted inventory guidelines. The model components can therefore be divided into sub-models of a similar nature (e.g. collection and transport) and of different treatment methods (e.g. recycling, incineration, landfilling, composting and swine feeding). The results were then used to arrive at a tally of their emissions' carbon equivalent.

\section{Methodology}

This work conceptually employed material flow method and WASTED model and considered the recycling of local kitchen waste which accounts for one third of the household wastes [5]. While looking at the emission of GHGs during the waste management process, apart from taking into account the effects for energy, raw materials and pollutant emissions before and after waste treatment practices, a compensatory treatment was also incorporated to justify the waste management system boundary $[5,6]$. The main purpose of this compensatory treatment was to internalize factors linked to external functions required by the entire waste management practices. Though these factors may not necessarily have a direct effect on the GHG emissions of the waste management system, they may still have an impact on the LCA. For example, recycling or re-manufacturing reduces the extraction of raw materials while the electricity generated by the incineration of waste matter may replace the fuel used in power generation. This provided a fairer basis for comparison of the environmental burdens of different treatment practices. The entire system therefore included the waste treatment and disposal of practice, the compensatory treatment, as well as the associated upstream and downstream systems. This was then analyzed and compared using the Life Cycle Inventory (LCI) method. For the input and output of energy, raw materials and pollutants derived from the recycled materials in the recycling

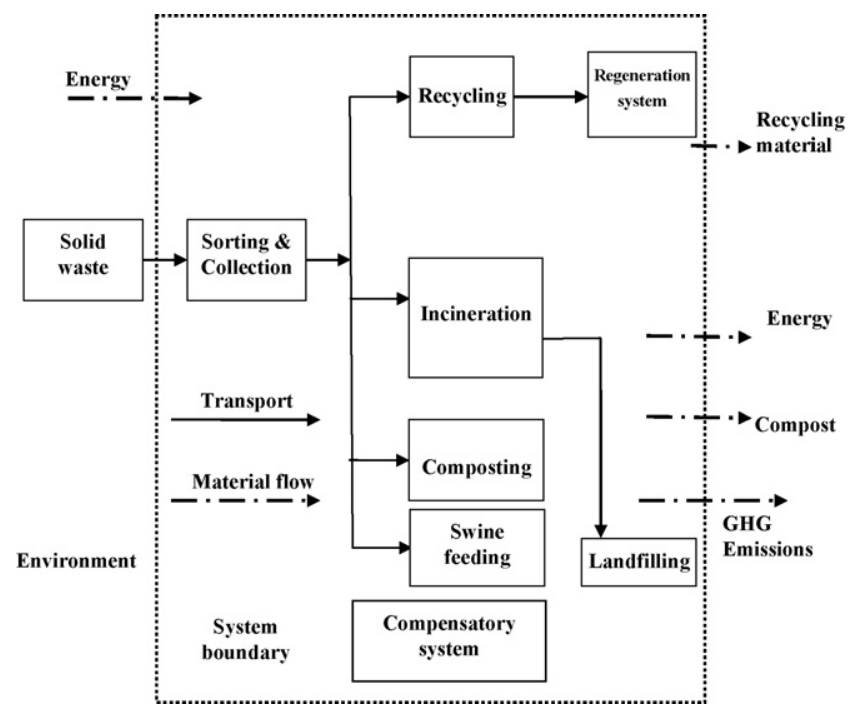

Fig. 1. System boundaries of conceptual model (adapted and modified from Eriksson et al. [2]).

practices, these were treated as intermediate products that terminate at the gate within the LCA $[7,8]$.

Waste management practices will behave differently due to regional differences [9]. Each material in municipal solid waste (MSW) would have different GHG emissions depending on the type of treatment method applied. In order to measure the GHG emission of local MSW, it was necessary to decide what waste will be analyzed and then select which GHGs to use for assessment. Taiwan's current waste classification categories were therefore used as the categories in waste analysis, while the treatment methods used the framework established by the existing waste management process for Taipei City. The environmental impact of GHG emissions from each component of the waste management practices was then assessed. The assessment began with the production of waste (discharged by household) through to the recycling of materials or its ultimate treatment and final landfill. The assessment of the process covered: waste volume, waste collection and transport, recycling, composting, swine feeding, incineration, energy recovery and landfill (Fig. 1).

For the above waste treatment practices, the basis used was per unit tonne of solid waste (functional unit) between initial collection and arrival at each treatment method type. For the life cycle of solid waste management, this included collection and transport, intermediate processing and final disposal (landfill). For the selection of GHG types, the gases that directly influenced the greenhouse effect $\mathrm{CO}_{2}, \mathrm{CH}_{4}$ and $\mathrm{N}_{2} \mathrm{O}$ were selected as the subjects for assessment [10]. As each type of GHG differed in the strength of their heat-trapping potential, the heat-trapping potential of $\mathrm{CO}_{2}(\mathrm{GWP})$ was used as the basis to show the level of relative contribution to global warming of each gas.

\subsection{GHGs emissions from the collection and transportation}

GHG emissions from the waste collection and transport mainly came from the $\mathrm{CO}_{2}$ generated by the transport vehicles' use of fuel. The actual emissions varied with the vehicles' engine 
Table 1

Waste collection and transportation vehicles' annual fuel consumption and emissions coefficient

\begin{tabular}{|c|c|c|c|c|c|}
\hline \multirow[t]{2}{*}{ Fuel category } & \multirow[t]{2}{*}{ Consumption $^{\mathrm{a}}$ (L/year) } & \multirow[t]{2}{*}{ Fuel thermal $^{\mathrm{b}}(\mathrm{GJ} / \mathrm{L})$} & \multicolumn{3}{|c|}{ Emissions $^{\mathrm{c}}(\mathrm{g} / \mathrm{MJ})$} \\
\hline & & & $\mathrm{CO}_{2}$ & $\mathrm{CH}_{4}$ & $\mathrm{~N}_{2} \mathrm{O}$ \\
\hline Petrol & 403,683 & 0.03435 & 72.098 & 0.006 & 0.043 \\
\hline Diesel & $3,238,475$ & 0.038136 & 72.098 & 0.003 & 0.002 \\
\hline
\end{tabular}

a Source: TDEP Division 3.

b Adapted from McDougall et al. [9, p. 123].

c Adapted from IPCC [10].

model, fuel type (petrol and diesel), size and load [11]. The total emissions could also be derived from the total mileage or fuel usage. As the uncertainty with using mileage was higher and garbage trucks also used their engines to power the hopper compactor during garbage collection and transportation, this study therefore used the fuel consumption of the transport vehicles as the basis for the calculations. Table 1 shows the annual fuel consumption of Department of Environmental Protection of Taipei City and the fuel's associated emission coefficients including the $\mathrm{CO}_{2}, \mathrm{CH}_{4}, \mathrm{~N}_{2} \mathrm{O}$ and fuel heating value.

The collection and transportation component in MSW's GHG emissions was therefore calculated using the following formula:

$E_{\mathrm{t}}=F_{i \mathrm{c}} \times H_{i} \times C_{i g} \times \mathrm{GWP}_{g} \times \frac{12}{44}$

$E_{\mathrm{t}}=\mathrm{GHG}$ carbon equivalence from collection and transportation of waste (kg CE/year);

$F_{i c}=$ amount of Fuel $i$ consumed (L/year, $i$ : fuel type such as diesel or petrol);

$H_{i}=$ the fuel heating value of Fuel $i(\mathrm{GJ} / \mathrm{L})$;

$C_{i g}=$ GHGs emission coefficient (g/MJ, $g$ : GHG type such as $\mathrm{CO}_{2}, \mathrm{CH}_{4}$ and $\mathrm{N}_{2} \mathrm{O}$ );

$\mathrm{GWP}_{g}=$ the GWP value of greenhouse gas $g$.

Data collected indicated that Taipei City's 198 waste collection routes and 4051 collection points were serviced each day by 198 continuously compacting garbage trucks and 286 recycling trucks of various vehicle models. The trucks weighed between 6.3 and 26 tonnes and were divided into four classes according to their weight (under 8 tonnes, 8-11 tonnes, 14-21 tonnes, over 21 tonnes). Within each class there were also further variations in operational fuel consumption (garbage compactor operation) due to differences in manufacturer, load type, engine capacity and hopper capacity. To calculate the GHG emissions from the engine caused by garbage compacting during garbage collection, we sampled 5 trucks at random in each class (20 trucks in total) then measured the number of compactor cycles and the fuel consumption from 20 min of continuous hopper compactor operation. The fuel consumption for each compactor cycle from all of the trucks was then added together and the mean calculated. This gave us an average consumption of $0.026 \mathrm{~L}$ (diesel) per compactor cycle per truck. As truck hopper capacities varied according to truck size, we also worked out that one compactor cycle was required per $1 \mathrm{~m}^{3}$ of waste collected. Using Taipei
City's 2005 household refuse density of $0.27 \mathrm{~kg} / \mathrm{L}$ [4], we estimated that each tonne of garbage compacted consumed $0.0963 \mathrm{~L}$ of diesel fuel, corresponding to GHG emissions of $0.0722 \mathrm{~kg} \mathrm{CE}$. The total amount of fuel consumed by garbage trucks for garbage compacting for the year was therefore $45,370 \mathrm{~L}$, corresponding to total GHG emissions of $34 \mathrm{MTCE}$. We then projected the diesel and petrol data using the surveyed vehicles' actual fuel consumption during transportation. Total fuel consumption of the garbage trucks was $2,808,873 \mathrm{~L}$ and from this we subtracted $45,370 \mathrm{~L}$ used for garbage compacting. This gave us a total fuel consumption amount during transportation of 2,763,503 L, corresponding to total GHG emissions of 2070.98 MTCE. Our calculations showed that each tonne of garbage collected consumed $5.8656 \mathrm{~L}$ of fuel, corresponding to GHG emissions of $4.3957 \mathrm{~kg} \mathrm{CE}$. This meant that during garbage collection, compacting and transit, garbage trucks generated $4.4679 \mathrm{~kg}$ CE per tonne of garbage collected. Recycling trucks used either diesel $(62 \%)$ or petrol $(38 \%)$ depending on their engine displacement and type. The collected kitchen waste was transported in barrels attached to the end of the compacting garbage trucks carrying other household waste. The fuel consumption was calculated according to the collected waste volume. The derived metric ton of carbon equivalent (MTCE) for each solid waste type collected and transported in Taipei City for 2005 is as shown in Table 2.

\subsection{GHGs emissions from recycling}

During the waste collection and recycling process, the materials were collected according to the above categories. These were then all sent to the material recovery facility (MRF) before being delivered to the factory for re-manufacturing. Generally apart from reducing the GHG emissions at the source, recycling created the least contribution out of all waste management solutions. This was because by using recycled matter instead of virgin material in the manufacturing process. It not only greatly reduced the demand for energy but also reduced nonenergy GHG emissions in the manufacturing process. Recycling of paper products in particular helped with forest carbon sequestration [3]. To calculate the reduction in GHG emission factors in recycling, the following factors were considered: (1) the difference in GHG emissions if an equal amount of recycled matter and virgin matter was introduced to the manufacturing process (taking into account the loss rate when re-manufacturing recycled matter); (2) forest carbon sequestration; (3) transport energy used in the manufacturing process; and (4) non-energy GHG emissions in the manufacturing process. 
Table 2

The fuel consumption and GHGs emissions for each solid waste category transported

\begin{tabular}{|c|c|c|c|c|c|c|c|}
\hline \multirow[t]{2}{*}{ Solid waste category } & \multirow[t]{2}{*}{ Waste transport (tonnes) } & \multicolumn{2}{|c|}{ Fuel consumption (L) } & \multicolumn{3}{|c|}{ Emissions (kg) } & \multirow[t]{2}{*}{ Gross GHGs emissions (MTCE) } \\
\hline & & Diesel & Petrol & $\mathrm{CO}_{2}$ & $\mathrm{CH}_{4}$ & $\mathrm{~N}_{2} \mathrm{O}$ & \\
\hline Household refuse $^{\mathrm{a}}$ & 471,138 & & & & & & \\
\hline Compacting & & 45,370 & - & 124,746 & 5.19 & 3.46 & 34.00 \\
\hline Collection and transit & & $2,763,503$ & - & 7598,333 & 316.17 & 210.78 & $2,070.98$ \\
\hline \multicolumn{8}{|l|}{ Recycled material } \\
\hline Flat category & 14,097 & 52,108 & 160,135 & 539,858 & 38.96 & 240.50 & 166.11 \\
\hline Solid category & 21,221 & 78,441 & 241,060 & 812,677 & 58.65 & 362.04 & 250.06 \\
\hline Home electrical appliances & 219 & 810 & 2,488 & 8,389 & 0.61 & 3.74 & 2.58 \\
\hline \multicolumn{8}{|l|}{ Kitchen waste } \\
\hline Composting & 39,512 & 235,566 & - & 647,696 & 26.95 & 17.97 & 176.53 \\
\hline Swine feeding & 10,513 & 62,677 & - & 172,332 & 7.17 & 4.78 & 46.97 \\
\hline Total & 556,700 & $3,238,475$ & 403,683 & $9,904,031$ & 453.70 & 843.27 & $2,747.23$ \\
\hline
\end{tabular}

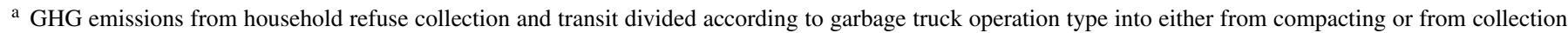
and transit.

The GHG emissions calculation was based on the assumption of the recycling being in a closed loop. These were classified using the TDEP's guidelines on recycling categories as shown in Table 3. The home electrical appliances category due to the variety of materials involved in their nature would definitely be an open loop in their recycling. Since home appliances and computers accounted for 141 and 78 tonnes of the total, they made up a relatively small fraction of the recycled materials and were neglected from the system. Using the recycling categories and quantities provided by the TDEP [4], taking into account the EPA's [3] GHG emission factors reduction and factoring in the conversion to surrogate material where a material belonged to no particular recycling category, this study calculated the reduction in emissions where recycled matter was used instead of virgin matter in the manufacturing process. This was represented in metric tons of carbon equivalent and listed in Table 3.

\subsection{GHGs emissions from incineration}

Taipei City's three incinerators treat waste using the cogeneration incineration method in the form of "mass burning". The GHGs produced during incineration were mainly $\mathrm{CO}_{2}$ and $\mathrm{N}_{2} \mathrm{O}$ [3]. The calculations for the incineration MSW's GHGs factors included: (1) emissions from the mass burning of MSW; (2) $\mathrm{CO}_{2}$ produced when generating power instead of utilities; and (3) the reduction in emissions caused by energy consumption due to the recovery of non-combustible metals for use in manufacturing. In accordance with the GHGs inventory guidelines developed by the IPCC [10], the biogenic $\mathrm{CO}_{2}$ produced by the combustion of paper, wood, bamboo, straw, leaf litter and kitchen waste were not factored into the calculations. The net emissions factors were therefore calculated as shown below:

$$
E_{\mathrm{n} i}=G_{\mathrm{e} i}-U_{\mathrm{e} i}-R_{\mathrm{em}}
$$

Table 3

Reduction in GHG emissions from using recycled materials instead of raw materials

\begin{tabular}{lccc}
\hline Material & Recycled (tonnes) & Emission factors (MTCE/tonne) & Emissions (MTCE) \\
\hline Flat category & & & $-9,313.64$ \\
$\quad$ Paper & 12,586 & -0.74 & -528.06 \\
$\quad$ Paper containers & 677 & -0.78 & -375.30 \\
$\quad$ Used clothing (textiles) & 834 & -0.45 & -921.24 \\
Solid category & & & $-1,712.34$ \\
$\quad$ Metal cans & 1,706 & -0.54 & $-6,944.36$ \\
Aluminum cans & 378 & -4.53 & -746.58 \\
Other metal products & 2,734 & -2.54 & $-2,055.15$ \\
PET bottles & 1,623 & -0.46 & -802.89 \\
Other plastic products & 4,567 & -0.45 & -319.50 \\
Glass containers & 8,921 & -0.09 & -721.68 \\
Tires & 710 & -0.45 & $-24,440.74$ \\
Others & 582 & $-1.24^{\mathrm{a}}$ & \\
Total & 35,318 & $-{ }^{\mathrm{b}}$ & \\
\hline
\end{tabular}

\footnotetext{
${ }^{a}$ The average value of waste paper, waste plastic and metal products was used to represent the surrogate material.

b Note that the total may not add up to $100 \%$ due to rounding.
} 
Table 4

Physical composition and volume of waste incinerated and the GHG emissions

\begin{tabular}{|c|c|c|c|c|}
\hline Material Combusted & Physical composition (\%) & Waste volume (tonne) & Net GHGs emission factor (MTCE/tonne) & GHG emissions (MTCE) \\
\hline \multicolumn{5}{|l|}{ Combustibles } \\
\hline Papers & 46.60 & 219,550 & -0.21 & $-46,105.50$ \\
\hline Textiles & 3.81 & 17,950 & 0.27 & $4,846.50$ \\
\hline Garden trimmings & 5.03 & 23,698 & -0.07 & $-1,658.86$ \\
\hline Kitchen wastes & 20.15 & 94,934 & -0.06 & $-5,696.04$ \\
\hline Plastics & 17.90 & 84,334 & 0.27 & $22,770.18$ \\
\hline Leather and rubber & 0.24 & 1,131 & 0.27 & 305.37 \\
\hline Others & 0.92 & 4,334 & -0.04 & -173.36 \\
\hline \multicolumn{5}{|l|}{ Incombustibles } \\
\hline Iron & 1.40 & 6,596 & -0.46 & $-3,034.16$ \\
\hline Other metal & 0.93 & 4,382 & -0.46 & $-2,015.72$ \\
\hline Glass & 2.35 & 11,072 & 0.01 & 110.72 \\
\hline Others ${ }^{\mathrm{a}}$ & 0.67 & 3,157 & $\mathrm{NA}^{\mathrm{b}}$ & $\mathrm{NA}$ \\
\hline Total & 100 & 471,138 & - & $-30,650.87$ \\
\hline
\end{tabular}

a As no emissions data was available on other types in the incombustible category such as brick, rock and ceramics these were discounted.

b NA: not available.

$E_{\mathrm{n} i}=$ net $\mathrm{GHG}$ emissions factor from material $i$ combusted at mass burn incinerator (MTCE/tonne, $i=$ type of combusted material; see Table 4);

$G_{\mathrm{e} i}=$ gross $\mathrm{GHG}$ emissions per tonne material $i$ combusted (MTCE/tonne);

$U_{\mathrm{e} i}=$ avoided utility $\mathrm{CO}_{2}$ per tonne material $i$ combusted at mass burn incinerator (MTCE/tonne);

$R_{\mathrm{em}}=$ avoided $\mathrm{CO}_{2}$ emissions per tonne combusted due to metal recovery (MTCE/tonne).

Apart from the recyclable materials, household waste was collected in mixture form so the types of waste and their relative fractions were used for the calculation based on the data provided by the TDEP [4]. The calculated results for the net metric ton of carbon equivalent emitted by the incineration of household waste are listed in Table 4.

\subsection{GHGs emissions from kitchen waste for composting}

Organic waste composting is a common treatment method to both developing and developed nations [12]. Taipei City began promoting and implementing the composting of organic kitchen waste in 2003 and most citizens now sort their waste prior to collection by the garbage trucks. The organic waste in the compost consisted mainly of leftovers, tea dregs, fruit peelings and yard trimmings [4]. The GHG emissions that may be produced by composting included: (1) $\mathrm{CH}_{4}$ generated by anaerobic decomposition; (2) carbon storage caused by long-term carbon compounds; (3) $\mathrm{N}_{2} \mathrm{O}$ produced by materials' initial nitrogen content; and (4) the non-biogenic $\mathrm{CO}_{2}$ emissions caused by the shipping of collected kitchen wastes to composting facilities and mechanical turning of the compost piles. The biogenic $\mathrm{CO}_{2}$ emissions cause by the composting process and the use of fertilizer on soil was discounted in accordance with the GHG inventory guidelines developed by the IPCC. Additionally, composting is an aerobic biological treatment method and if perfectly carried out, $\mathrm{CH}_{4}$ is generally not generated. The $\mathrm{CH}_{4}$ produced at the center of the compost pile, most likely oxidized when it reaches the oxygen-rich surface of the pile, where it be converted to $\mathrm{CO}_{2}[3,12]$ or may be emitted due to unintentional leakages during process disturbances [12]. To assess the GHG emissions created by compost, the IPCC [12] emission factors for $\mathrm{CH}_{4}\left(4 \mathrm{~g} \mathrm{CH}_{4} / \mathrm{kg}\right.$ waste treated) and $\mathrm{N}_{2} \mathrm{O}\left(0.3 \mathrm{~g} \mathrm{~N}_{2} \mathrm{O} / \mathrm{kg}\right.$ waste treated) were used. After conversion the MTCE for $\mathrm{CH}_{4}$ and $\mathrm{N}_{2} \mathrm{O}$ were as shown in Table 5 . As for the indirect production of $\mathrm{CO}_{2}$ from transportation of kitchen waste to compost site and the turning of compost piles with machinery, these were assessed in accordance with EPA [3] estimates as 0.011 MTCE. The GHG emissions were therefore calculated as shown below:

$\mathrm{GHG}_{\mathrm{E}}=\Sigma\left(M \times C_{i}\right)$

$\mathrm{GHG}_{\mathrm{E}}=$ total volume of greenhouse gases emitted (MTCE); $M=$ amount of organic waste composted (tonne);

$C_{i}=$ emission factor for greenhouse gas $i$ for treating each tonne of waste (MTCE/tonne; $i$ : GHG type such as $\mathrm{CO}_{2}, \mathrm{CH}_{4}$ and $\mathrm{N}_{2} \mathrm{O}$ ).

As the adding of organic matter to soil through compost increased the soil's carbon level, this helped make up for the reduction in carbon content caused by an increase in crop yields or other soil activities. Stable carbon compounds created by composting process included an increase in humic substances and aggregates allowing carbon to be stored long periods of time in the soil. The carbon storage potential created by compost was therefore also taken into consideration in this study. The soil carbon restoration and increased humus formation factor values were used to derive the EPA [3] carbon storage factor for soil and when tallied resulted in its net GHG emissions, or "net carbon flux". This emission factor had a value of $-0.055 \mathrm{MTCE} /$ tonne. Kitchen waste compost's MTCE values are as shown in Table 5 . 
Table 5

GHG emissions factors and volume from composting of organic waste

\begin{tabular}{|c|c|c|c|c|c|c|}
\hline Treatment method & Waste (tonnes) & $\begin{array}{l}\mathrm{CH}_{4} \text { emission } \\
\text { factor } \\
\text { (MTCE/tonne) }\end{array}$ & $\begin{array}{l}\mathrm{N}_{2} \mathrm{O} \text { emission } \\
\text { factor } \\
\text { (MTCE/tonne) }\end{array}$ & $\begin{array}{l}\mathrm{CO}_{2} \text { emission } \\
\text { factor } \\
\text { (MTCE/tonne) }\end{array}$ & $\begin{array}{l}\text { Net carbon flux } \\
\text { (MTCE/tonne) }\end{array}$ & $\begin{array}{l}\text { Gross GHG } \\
\text { emissions } \\
\text { (MTCE) }\end{array}$ \\
\hline Composting & 39,512 & $2.268 \times 10^{-2}$ & $2.511 \times 10^{-2}$ & $1.1 \times 10^{-2}$ & $-5.5 \times 10^{-2}$ & 149.75 \\
\hline
\end{tabular}

Note a negative value denotes carbon storage, a positive value denotes emissions.

\subsection{GHGs emission from landfilling}

Beginning operation in 1998, the Taipei City Sanitary Landfill has been used to bury incombustible waste, incinerator slag, biological sludge and gutter sludge. It uses the anaerobic sandwich sanitary landfill method [4]. Household waste that is compulsory sorting and recycling was imposed with only incombustible trash allowed to enter the landfill. It has been verified in many countries that this policy of restricting waste types allowed at landfills produces only a small amount of pollutants and reduces the need for landfill sites [9].

This study focused on the waste management strategy for household garbage so gutter and biological sludge were not included into the system. As the breakdown of organic substances mainly came from biomass sources, this part was not included in the GHG emission estimates in line with IPCC recommendations. As $\mathrm{N}_{2} \mathrm{O}$ emissions were insignificant at the landfill so this part was also discounted [3,12]. In evaluating GHG emissions from organic waste and mixed MSW buried in the landfill, the main items were therefore $\mathrm{CH}_{4}$ emissions and $\mathrm{CO}_{2}$ produced during transportation and carbon storage [3]. $\mathrm{CH}_{4}$ can be chemically oxidized or converted by bacteria to $\mathrm{CO}_{2}$. This part was assumed to be $10 \%$ of the total $\mathrm{CH}_{4}$ output. Emissions from landfills are affected by the site facilities design, methane collection system and type of buried waste. $\mathrm{CH}_{4}$ generation does not start immediately after burial; $\mathrm{CH}_{4}$ is observed a certain time after burial and continuing even after the landfill is decommissioned. The landfill gas (LFG) recovery rate in particular has a big influence on the net GHG emissions due to the greater GWP value of $\mathrm{CH}_{4}$. The effect of these variations in net emissions will affect the choice of MSW management strategy so for this study the average LFG recovery rate was set at $75 \%$. For GHG emissions from the transportation of different waste treatment methods' residue, these were in principle calculated based on the actual fuel consumption during transportation. Where no data was available the default values defined by the EPA [3] were used to set its carbon equivalence as 0.011 MTCE per tonne of residue.

As the ash from complete incineration contained no organic carbon when it arrives at the landfill, the burial of ash would generate no LFG. No incineration will completely remove the carbon but it can be assumed that the landfill of incinerator ash will result in no LFG emissions [9]. The incineration of waste usually resulted in ash containing $15-20 \%$ of the original mass. Taipei City's three incinerators on average had a load of $83.65 \%$, standing for that each metric ton of garbage incinerated resulted in 0.16 metric ton of ash. Therefore, with Taipei City's waste management policy in 2005 of requiring all household waste to be incinerated before landfill, the net GHG emissions generated at the landfill could have only come from transportation of ash to the landfill site. According to the information in Table 2, this was estimated to be 344.16 MTCE.

Table 6

Net GHG emissions from landfilling

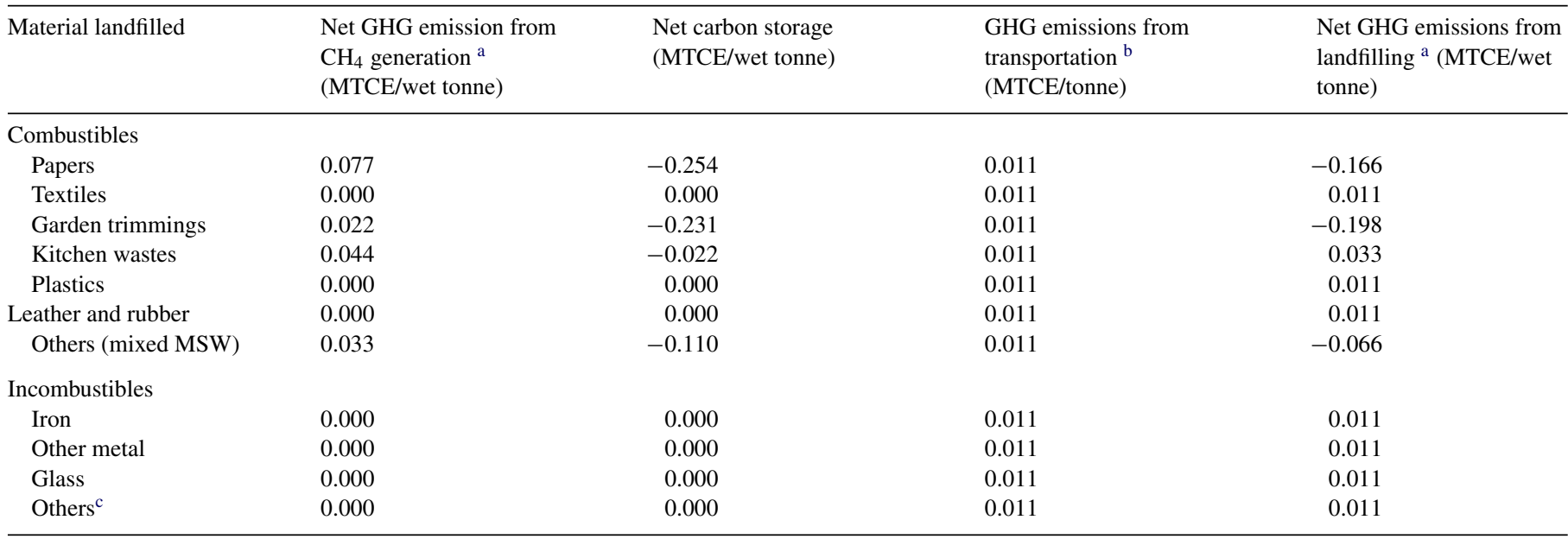

Note that total may not add due to rounding.

a Landfills with LFG recovery and electric generation.

${ }^{b}$ Default value for GHG emissions during transportation from EPA [3].

${ }^{c}$ Other materials in the incombustible category such as ash, brick, stone and ceramics. 
Table 7

GHG emissions factors and volume from swine feeding to treat organic waste

\begin{tabular}{|c|c|c|c|c|c|c|}
\hline Treatment method & Waste (tonnes) & $\begin{array}{l}\text { GHG emissions factor } \\
\text { from transportation } \\
\text { (MTCE/tonne) }\end{array}$ & $\begin{array}{l}\mathrm{CO}_{2} \text { emission factor from } \\
\text { heating (MTCE/tonne) }\end{array}$ & $\begin{array}{l}\text { Gross } \mathrm{CH}_{4} \\
\text { emission factor } \\
\text { (MTCE/tonne) }\end{array}$ & $\begin{array}{l}\mathrm{N}_{2} \mathrm{O} \text { emission } \\
\text { factor } \\
\text { (MTCE/tonne) }\end{array}$ & $\begin{array}{l}\text { GHGs emissions } \\
\text { (MTCE) }\end{array}$ \\
\hline Swine feeding & 10,513 & $1.1 \times 10^{-2}$ & $2.2 \times 10^{-4}$ & $1.14 \times 10^{-2}$ & $2.62 \times 10^{-4}$ & 240.56 \\
\hline
\end{tabular}

However, to provide a more complete framework of waste management strategy, it can be compared with the direct to landfill treatment method used by other cities. The collected results from the analyzing of net GHG emissions from landfill waste composition are as shown in Table 6.

\subsection{GHGs emissions from swine feeding}

Kitchen waste for swine feed is one of the waste recycling categories with free collection and transport. Unlike kitchen waste for composting, it consists of organic waste edible residual material to pigs such as leftover rice, meat and expired foods [4]. As kitchen waste is one of the MSW processing categories, when it is used for swine feeding the livestock becomes the source of $\mathrm{CH}_{4}$ and $\mathrm{N}_{2} \mathrm{O}$. When assessing the $\mathrm{CH}_{4}$ emissions in the GHG from using kitchen waste to feed pigs, two emission sources must therefore be considered-swine's enteric fermentation and manure management [10].

The kitchen waste was collected together with household waste and then put together at the transfer station. From there it was transported by pig industry operators to the pigpens. In accordance with Environmental Protection Administration of Taiwan regulations the kitchen waste must be sterilized by steam cooking at $90^{\circ} \mathrm{C}$ and stirred for over an hour before it can be fed to pigs. During this process, apart from the emissions generated due to the use of energy for transportation, the $\mathrm{CO}_{2}$ generated by the energy used for cooking was also factored into the calculation of GHG emissions for the kitchen waste for swine feeding sub-model $\left(\mathrm{N}_{2} \mathrm{O}\right.$ and $\mathrm{CH}_{4}$ emissions is extremely low by comparison so not included). An inventory showed that pig industry operators used heavy fuel oil to power the steam boiler needed to cook the kitchen waste. On average $11 \mathrm{~L}$ of oil were consumed for each tonne of kitchen waste. Heavy fuel oil has a density of $920 \mathrm{~kg} / \mathrm{m}^{3}$ with fuel calorific value of $41.7 \mathrm{MJ} / \mathrm{kg}$ [11] and carbon emissions factor of $20.2 \mathrm{tC} / \mathrm{TJ}$ [10]. When the heavy oil used to heat each tonne of kitchen waste was calculated and converted, this resulted in carbon emissions equal to $2.2 \times 10^{-4}$ MTCE. As for the GHG emissions generated when transporting the kitchen waste from the transfer station to the pigpens, as no relevant fuel consumption figures were available, the default values from the EPA [3] were used to give an estimate of 0.011 MTCE for each tonne of kitchen waste.

Factors that needed to be considered when calculating methane emissions from pigs included: swine populations and emissions factors (enteric fermentation emissions factor, manure management emissions factor). Each pig could digest approximately $5-10 \mathrm{~kg}$ of kitchen waste each day. This meant the collected kitchen waste could feed around 3840 pigs a year. Tai- wan is located in a sub-tropical region and the Weather Bureau gave the average monthly temperature for 2005 as $23.3^{\circ} \mathrm{C}$. Based on these climate conditions, the corresponding IPCC enteric fermentation and manure management emissions factors were 1.5 and $4(\mathrm{~kg} / \mathrm{head} /$ year), respectively [10]. Multiplying the number of pigs by the emissions factors then summing the results provided total $\mathrm{CH}_{4}$ emissions of 21.12 tonne/year, the equivalent of $119.75 \mathrm{MTCE} / \mathrm{year}$. There was very limited data available on the $\mathrm{N}_{2} \mathrm{O}$ emissions from manure management. The emission concentration was also affected by a wide variety of factors resulting in a large range of concentrations $\left(<10^{-4}\right.$ to $>0.15 \mathrm{~kg} \mathrm{~N} / \mathrm{kg}$ nitrogen). Generally speaking each kilogram of dry matter in animal feed contained $10-40 \mathrm{~g}$ of nitrogen [10]. Due to the complicated composition of kitchen waste and the absence of data on its nitrogen content per kilogram, it is assumed that each tonne of kitchen waste had a nitrogen content of $25 \mathrm{~kg}$. The Groenestein et al. [13] study measured the nitrogen emissions for pigs over a period of four months. The resultant $\mathrm{N}_{2} \mathrm{O}$ value $(0.15 \mathrm{~kg} / \mathrm{kg}$ nitrogen $)$ was used in this study as the emission factor. After converting the calculations each tonne of kitchen waste resulted in a carbon equivalent value for $\mathrm{N}_{2} \mathrm{O}$ emissions from manure management equal to $2.62 \times 10^{-4}$ MTCE.

Apart from the GHG emissions produced during transport, collecting kitchen waste for swine feeding also created GHG emissions was assessed under the domestic livestock category of agricultural activities. These included: $\mathrm{CH}_{4}$ emissions from enteric fermentation, $\mathrm{CH}_{4}$ emission from manure management and $\mathrm{N}_{2} \mathrm{O}$ emissions from manure management [10]. The results from using these items to assess GHG emissions for this submodel are shown in Table 7.

\section{Major limitations}

The analysis and use of parameters in this study drew upon a great deal of analytical approaches and data sources. All of these had their research limitations. Additionally, the analyses and assessments in this model framework made a few major assumptions. The major limitations in the study and from the assumptions are shown as below:

- The GHG analysis for the downstream transportation fuel consumption, acquisition of raw materials and the manufacturing industry were all based on the average industry values. GHG analysis for electric generation was also based on limited data and average values.

- In forest carbon sequestration related assessment and analysis, Taiwan is in fact also influenced by the amount of waste paper 
imports and non-forest wood pulp (e.g. bamboo and hemptype plants). The lack of available data necessitated the use of GHG default values from the U.S. EPA [3].

- The net GHG pollutants produced by the incineration of waste can be reduced through improvements to the efficiency of the incineration system. The discrepancy between different incinerators was therefore not reflected in this study and the parameters used for analysis were based on the U.S. national average (e.g. recovery of incombustible metal).

- The pollutant emissions from composting depended on the types/quantities of supporting material as well as the temperature, water content and supply of oxygen during the composting process. This led to a wide range of emission volumes so for the analysis of emissions the default $\mathrm{CH}_{4}$ and $\mathrm{N}_{2} \mathrm{O}$ values for compost from the IPCC [12] were used.

- The landfill analysis was based on the household waste treatment method for 2005. A lack of relevant data on $\mathrm{CH}_{4}$ emissions from the landfill surface and carbon storage meant there were a large number of uncertainties involved.

- The nitrogen content of kitchen waste was the main factor that influenced $\mathrm{N}_{2} \mathrm{O}$ emissions once it was fed to pigs. The composition of the kitchen waste however was linked to residents' diet and consuming capability. Due to a lack of information on the nitrogen content of kitchen waste, the average nitrogen content of animal feed was used instead. The emission factor used was also the default value used by the IPCC [10] for pig keeping in general agriculture according to certain climate conditions.

Finally, the aim of this study was to establish localized assessment methods that waste management agencies, environmental engineers and environmental policy decision makers can use to quantify and compare the contribution to the greenhouse effect from different waste management programs. Though the types and quantities of waste used existing Taiwan statistical data and technical terms as much as possible in order to reduce the uncertainty in parameter use, the assessment and analysis methods still used point estimate for the system's inputs and outputs. With much of the data used in the life-cycle impact assessment coming from a variety of sources and the parameters used being estimations or average values, the reliability of the results is hard to assess. Though uncertainty and variability could be overcome through meticulous methodology, in reality the statistical data and information required for a proper examination was simply not available.

\section{Results and discussion}

For a developed country when dealing with the environmental effects of waste disposal, their waste/sewage discharge and treatment technologies have already been developed to a certain standard and level of uniformity. The major factor governing the GHG generated during the waste management process is therefore the physical composition of the waste itself as well as the choice of treatment method and policy. The quantity and physical composition of the waste is in turn governed by the local residents' lifestyles, material consumption power and cooperation with management policy. When assessing the emission of GHGs during the regional waste management process the nature and quantity of the local waste should be examined. It should also be analyzed item by item according to the actual treatment method used to provide a reference in GHG emission reduction policy decisions. In this study, the current physical composition and treatment methods of Taiwan's waste were examined. The study discovered that recycling offered the best reduction of GHG emissions among the waste treatment methods while using kitchen waste as swine feeding resulted in the most GHG emissions. As the sanitary landfill only permits the burial of household waste after it has been incinerated and reduced to ash, this prevents the generation of methane at the landfill site and has a positive effect on GHG emission reduction. The GHG emissions from the fuel used by transportation vehicles in the different treatment methods however have a negative effect on GHG emission reduction. GHG emissions from transportation should therefore be taken into consideration when formulating a GHG reduction strategy. Classification and summarization the net carbon equivalence of GHG emissions from each of the waste treatment methods within Taipei City's solid waste management system are shown in Table 8.

The IPCC does not count the $\mathrm{CO}_{2}$ generated from the combustion of biogenic matter while the electricity generated by the incinerator can replace some of the $\mathrm{CO}_{2}$ produced by power plants' fuel use. This results in recycling kitchen waste as swine feeding and for composting having higher GHG emissions than

Table 8

Net GHGs emissions from solid waste treatment methods in Taipei

\begin{tabular}{|c|c|c|c|c|c|}
\hline Treatment categories & Waste (tonne) & $\begin{array}{l}\text { GHGs emissions from } \\
\text { transportation (MTCE) }\end{array}$ & $\begin{array}{l}\text { GHGs emissions } \\
\text { from treatment } \\
\text { (MTCE) }\end{array}$ & $\begin{array}{l}\text { Net GHGs emissions } \\
\text { from treatment } \\
\text { (MTCE) }\end{array}$ & $\begin{array}{l}\text { Net GHGs emissions } \\
\text { for functional unit } \\
\text { (MTCE/f.u.) }\end{array}$ \\
\hline Recycling & 35,318 & 416.17 & $-24,440.74$ & $-24,024.57$ & $-6.80 \times 10^{-1}$ \\
\hline Incineration & 471,138 & 2104.98 & $-30,650.87$ & $-28,545.89$ & $-6.06 \times 10^{-2}$ \\
\hline Composting & 39,512 & 176.53 & 149.75 & 326.28 & $8.26 \times 10^{-3}$ \\
\hline Swine feeding & 10,513 & 46.97 & 240.56 & 287.53 & $2.73 \times 10^{-2}$ \\
\hline Landfill & 77,031 & 344.16 & - & 344.16 & $4.47 \times 10^{-3}$ \\
\hline Total & 633,512 & 3088.81 & $-54,701.30$ & $-51,612.49$ & - \\
\hline
\end{tabular}

Note negative numbers indicate avoided emissions ("credits"). 


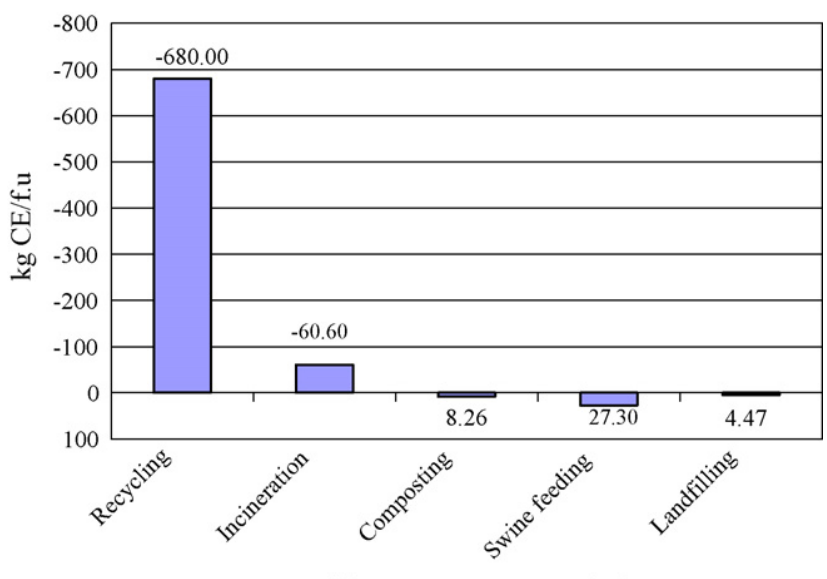

Solid waste treatment method

Fig. 2. Comparison of GHGs carbon equivalent in each treatment method.

burying incinerator ash at landfills. It can be seen in the GHG carbon equivalence produced by each function unit in the different treatment methods (see Fig. 2). The GHG resulting from the recycling of kitchen waste is provided as a reference for decision makers.

\section{Conclusion}

The contribution to GHG emissions made by a regional waste management policy can be clearly quantified through life-cycle assessment. The assessment and inventory model used here provide not only a reference for the central and local governments of Taiwan in their waste management policy but also is used internationally to express Taiwan's GHG emissions and reduction results.

Waste management strategy in Taiwan favored incineration due to local considerations (difficulty of land acquisition) and a policy of promoting energy recovery through maximizing extraction of calorific value from waste. The results from the assessment indicated that using this method to produce ash then disposing it in a landfill is a positive contribution to reducing GHG emissions. To achieve the objectives of waste reduction and boosting recycling volumes, Taipei waste management policy implemented free collection for recyclable waste. This initiative has evidently helped to reduce GHG emissions. As for the GHG emissions generated by transport vehicles' fuel use, the possibility of making improvements through reducing collection frequency and the number of collection points should be assessed.

\section{References}

[1] S.S.M. ASCE, T. Aramaki, Y. Hwang, K. Hanaki, Environmental impact of solid waste treatment methods in Korea, J. Environ. Eng. 130 (1) (2004) $81-89$.

[2] O. Eriksson, B. Frostell, A. Björklund, G. Assefa, J.-O. Sundqvist, J. Granath, M. Carlsson, A. Baky, L. Thyselius, ORWARE-a simulation tool for waste management, Resour. Conserv. Recycle 36 (4) (2002) 287-307.

[3] Environmental Protection Agency (EPA), Solid Waste Management and Greenhouse Gases. A Life-cycle Assessment of Emissions and Sinks, second ed., US Environmental Protection Agency, Washington, DC, 2002 (EPA530-R-02-006).

[4] Department of Environmental Protection of Taipei City Government (TDEP), 2005 Yearbook of Environmental Protection Statistic (in Chinese), Taiwan, 2006.

[5] R. Diaz, M. Warith, Life-cycle of municipal solid wastes: development of the WASTED model, Waste Manage. 26 (2006) 886-901.

[6] A. Baky, O. Eriksson, Systems Analysis of Organic Waste Management in Denmark, Danish Environmental Protection Agency, Copenhagen, Denmark, 2003.

[7] I. Hamerton, A. Emsley, A. Azapagic, Polymers the Environment and Sustainable Development, John Wiley, West Sussex, England, 2003, pp. $128-130$.

[8] J.B. Guinée, Handbook on Life Cycle Assessment Operational Guide to the ISO Standards, Kluwer Academic Publishers, Netherlands, 2002.

[9] F. McDougall, P. White, M. Franke, P. Hindle, Integrated Waste Management: A Life Cycle Inventory, second ed., Blackwell Science, Oxford, UK, 2001.

[10] IPCC, Revised 1996 IPCC Guidelines for National Greenhouse Inventories, in: J.T. Houghton, L.G. Meira Filho, B. Lim, K. Tréanton, I. Mamaty, Y. Bonduki, D.J. Griggs, B.A. Callander (Eds.), Intergovernmental Panel on Climate Change (IPCC), IPCC/OECD/IEA, Paris, France, 1997.

[11] A.S.H. de Beaufort-Langeveld, R. Bretz, G. van Hoof, R. Hischier, P. Jean, T. Tanner, M. Huijbregts (Eds.), Code of Life-Cycle Inventory Practice, Society of Environmental Toxicology and Chemistry (SETAC), Pensacola, FL, USA, 2003, p. 160.

[12] IPCC, in: H.S. Eggleston, L. Buendia, K. Miwa, T. Ngara, K. Tanabe (Eds.), 2006 IPCC Guidelines for National Greenhouse Gas Inventories, Prepared by the National Greenhouse Gas Inventories Programme, IGES, Japan, 2006.

[13] C.M. Groenestein, J. Oosthoek, H.G. van Faassen, Microbial processes in deep-litter systems for fattening pigs and emissions of ammonia, nitrous oxide and nitric oxide, in: M.W.A. Verstegen, et al. (Eds.), Nitrogen flow in Pig Production and Environmental Consequences, Proceeding First International Symposium on Nitrogen Flow in Pig Production and Environmental Consequences, Pudoc Scientific Publishers, Wageningen, 1993, pp. 307-312. 